\title{
Enhancing the General and Special Skills of Students
}

\author{
Nikolinka Hinkova, Nikolay Nenov \\ TU-Gabrovo, BG 5300 Gabrovo Str. Hadji Dimitar 4
}

\begin{abstract}
The paper discusses some specific features related to the practical training of students of the Technical University of Gabrovo (Bulgaria) in some specific companies.
\end{abstract}

Keywords: practice, firm, training, modernization, students, new machines and technologies, economization

\section{INTRODUCTION}

In recent years, the need to deepen the relationship between theory and practice is increasingly felt. On one hand, requirements of the manufacturers are getting higher, which is related to the firms' natural growth and competitiveness, on the other hand, the introduction of science and technology in almost all spheres of public life requires the involvement of a growing number of highly qualified professionals not only with specialized secondary education, but also with higher technical education.

In Bulgaria, the real need for professionals is becoming more and more tangible over time. Because of the deplorable economic condition of the country most of the best university graduates seek job opportunities in countries offering a reward several times better. This in turn leads to an even greater crisis in the economy, as the state has in one way or another invested in education without actually being able to recover this huge investment.

These issues have been discussed more than once. Moreover, in order to make things happen in the right direction, the so called political will is necessary, which is not always in the public interest. Current events in the country in recent months and the fall of the government are other shining examples of this.

\section{THEORETICAL GROUNDING OF THE RESEARCH}

At the Technical University of Gabrovo, (Gabrovo is a town which had the greatest number of industrial enterprises in Bulgaria until the year 2000) we are continuing to look for a formula meeting in the most complete way the growing need of society for generating more and more not only knowledgeable, but also capable young people. In this regard, the relationship between universities and business is of particular importance. In Gabrovo, there are currently only a few industrial enterprises, but some of them, such as the Bulgarian-Swiss company "Mechatronica" (Fig.1), the German-Bulgarian company "AMK", the Austrian-Bulgarian company "Instrument" and some others, perform at a modern European level.

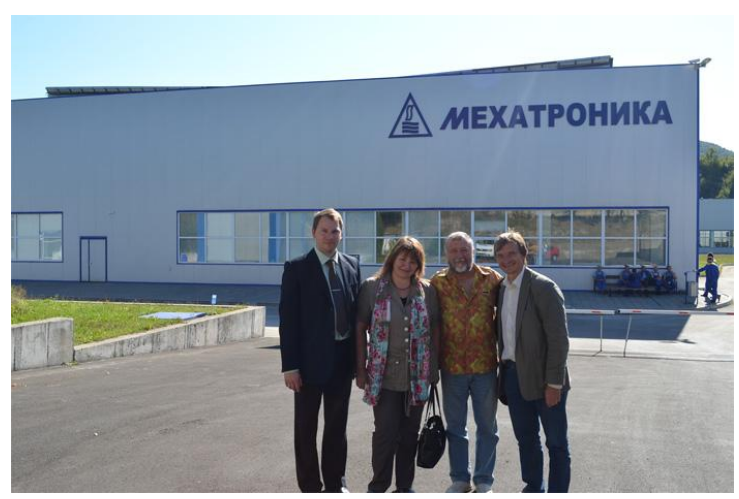

Fig.1. Company "Mechatronica" building

This makes it possible for some of the town's graduates and university students to find professional realization in an area where they can prove their knowledge and skills. The skills, however, are those which the graduating engineers and technicians mostly lack. In this regard, the very innovative company "Mechatronica", feeling the lack of well prepared and trained young people for its high-tech developments and production (Fig. 2, Fig. 3), established a specialized Training and Production Center (Fig. 4).

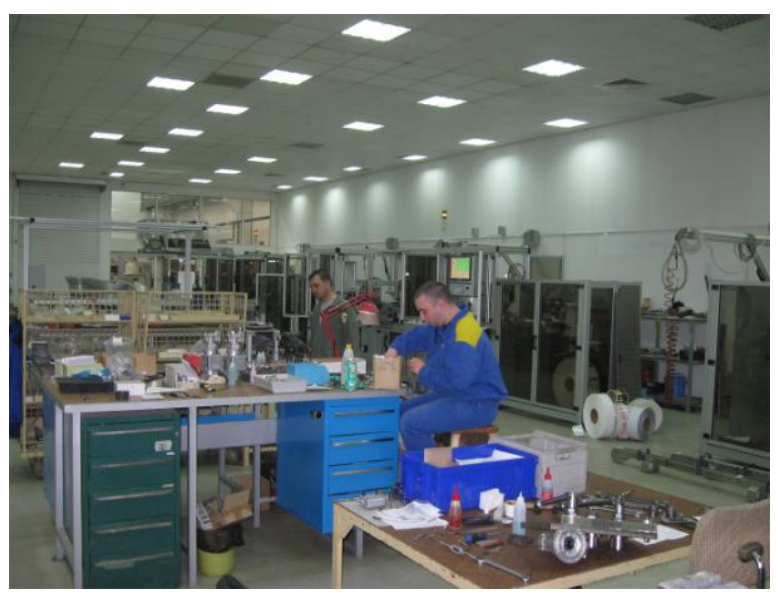

Fig.2: Assembly sector of the "Mechatronica" company 


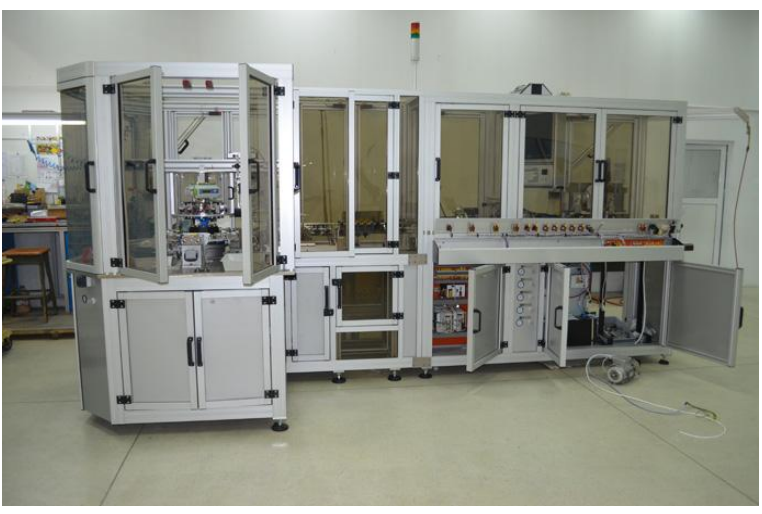

Fig. 3: A module of high-tech manufacturing

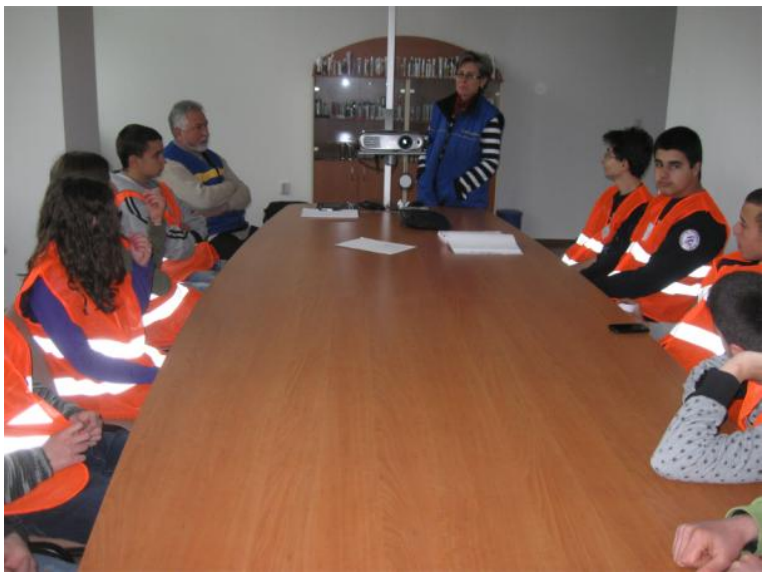

Fig. 4: Part of the newly opened Training Centre

The main objective of this Center is the development of the relationship between theory and practice in order to ensure production with promising personnel among both high school graduates (Figure 4) and university graduates (Figure 5).

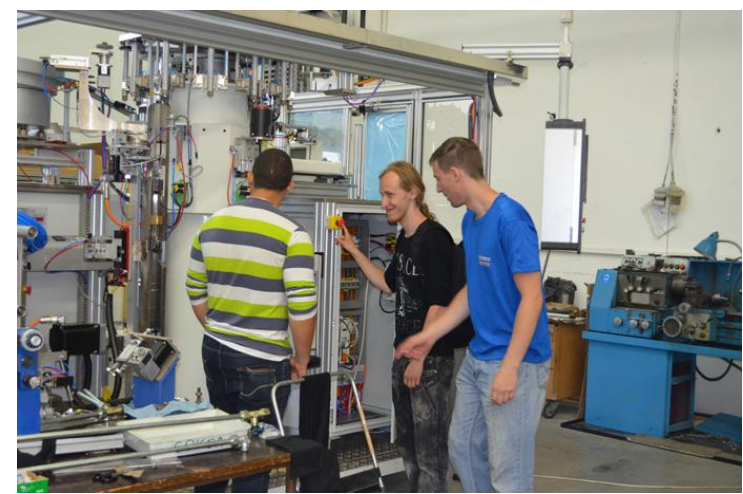

Fig. 5: Soldering of electronic components on a printed circuit boar

In creation of a training center, the students who were on training at "Erasmus" program in the same company helped a lot. (Fig.6).

Students who are passing training, are trained on the newest elements in the development of the firm "Mechatronics". (Fig.7)

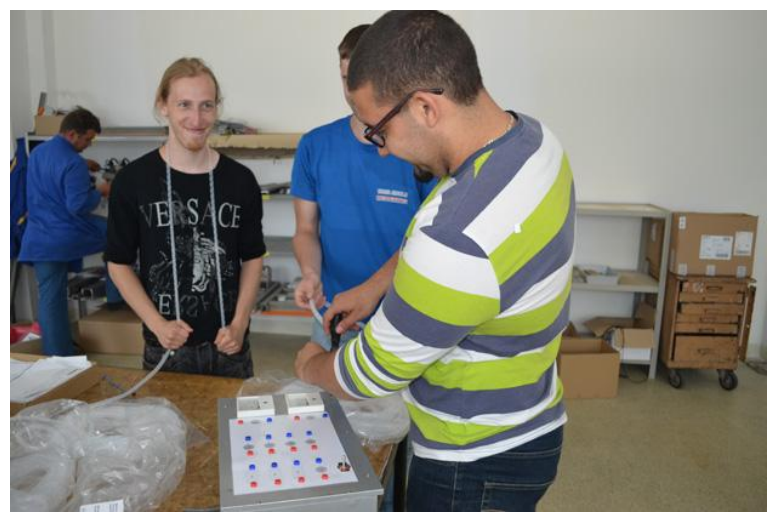

Fig.6: Making one of the stands for teaching the basics of electrical engineering

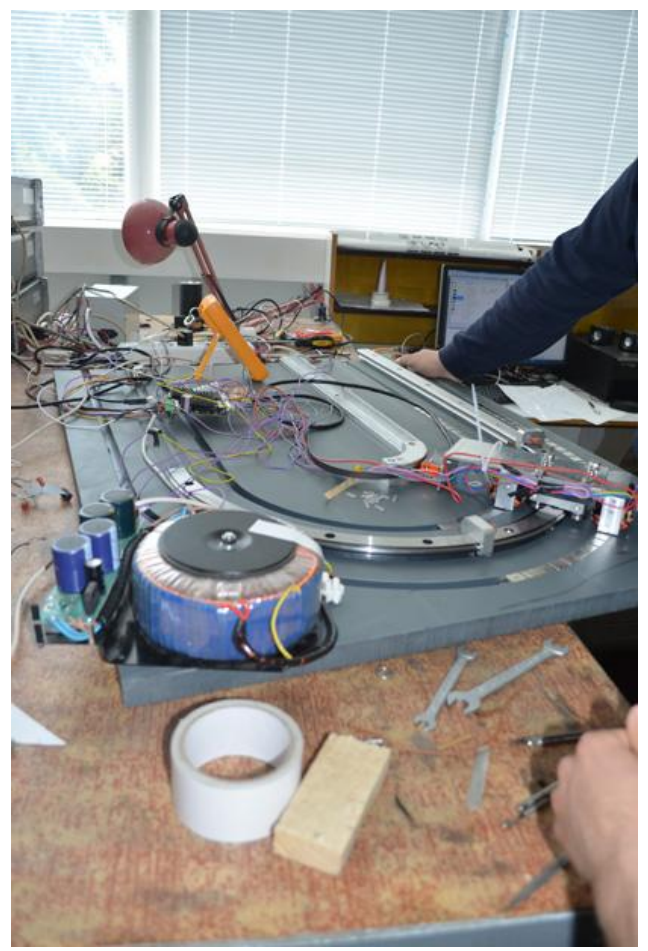

Fig.7: Students whom show a linear motor control

Besides the "Mechatronics" company Gabrovo city offers a training possibilities to students in other specialties. For example, the company "Impuls" AD is open to an internship and practice of both our and foreign students. (Fig.8), (Fig.9).

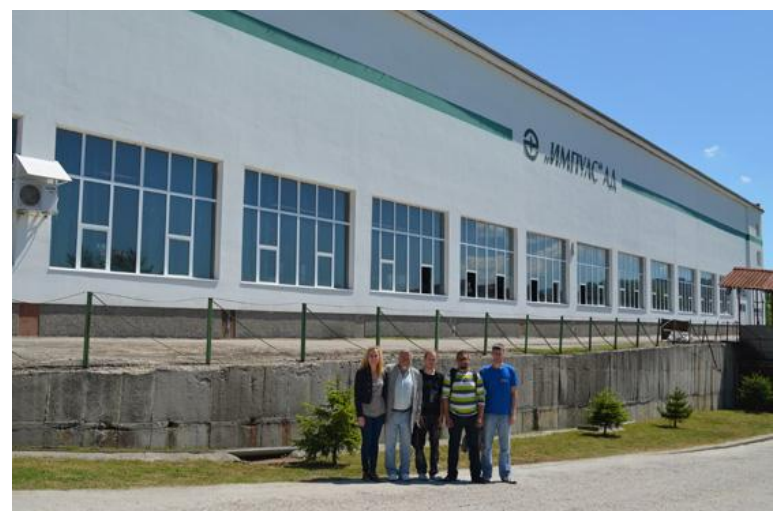

Fig.8: Company „Impuls” AD building 


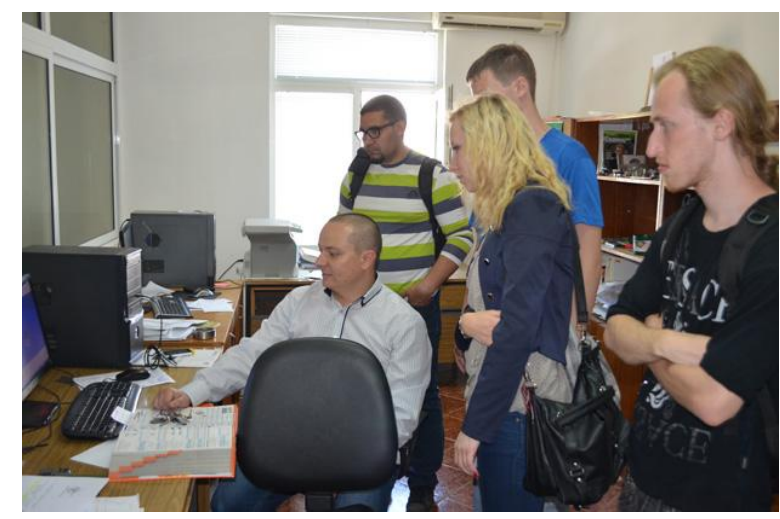

Fig.9: Showing the capabilities of modern software design of complex parts in $3 \mathrm{D}$ format

In year 2013 in the territory of the plant a student from the Republic of Latvia Laura Cipruse held a practice. (Fig.12) Which is learning in programme "Environment Engineering". Attracted particular interest to her was the segment electroplating (Fig.10), where it was an opportunity to be familiar in details with work of modern sewage treatment plant (Fig.11).

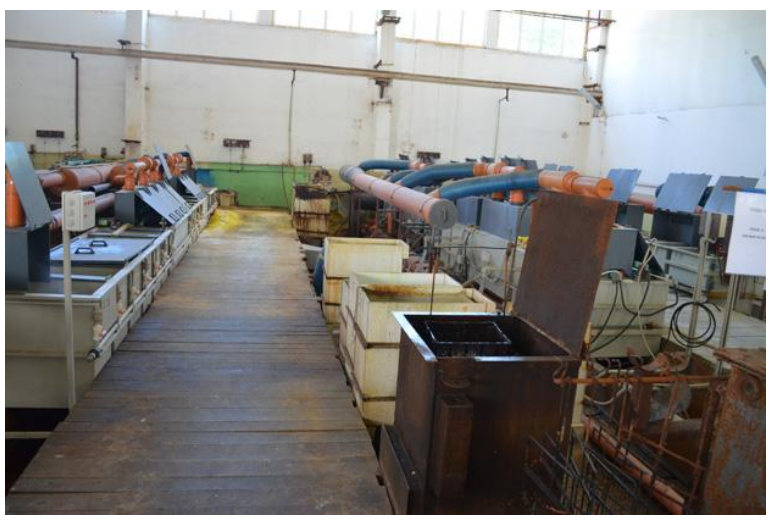

Fig.10: Section for electroplating

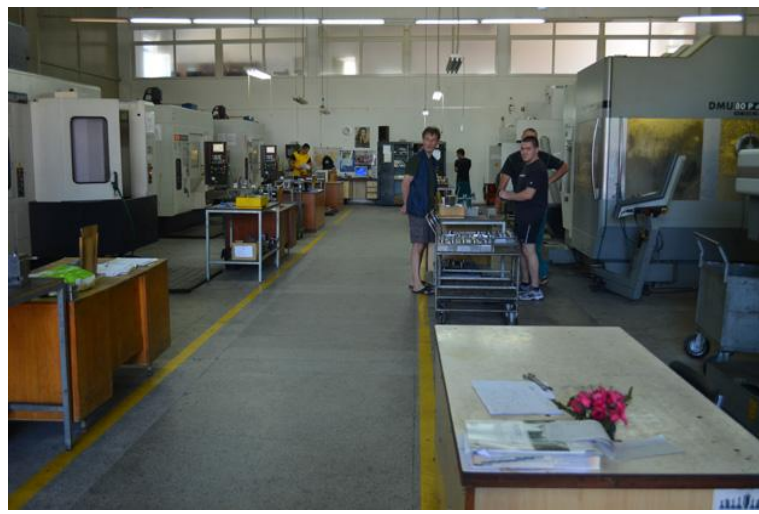

Fig.11: General view of one of the workshops where precisely are processed parts for medical equipment using modern machines with digital program control

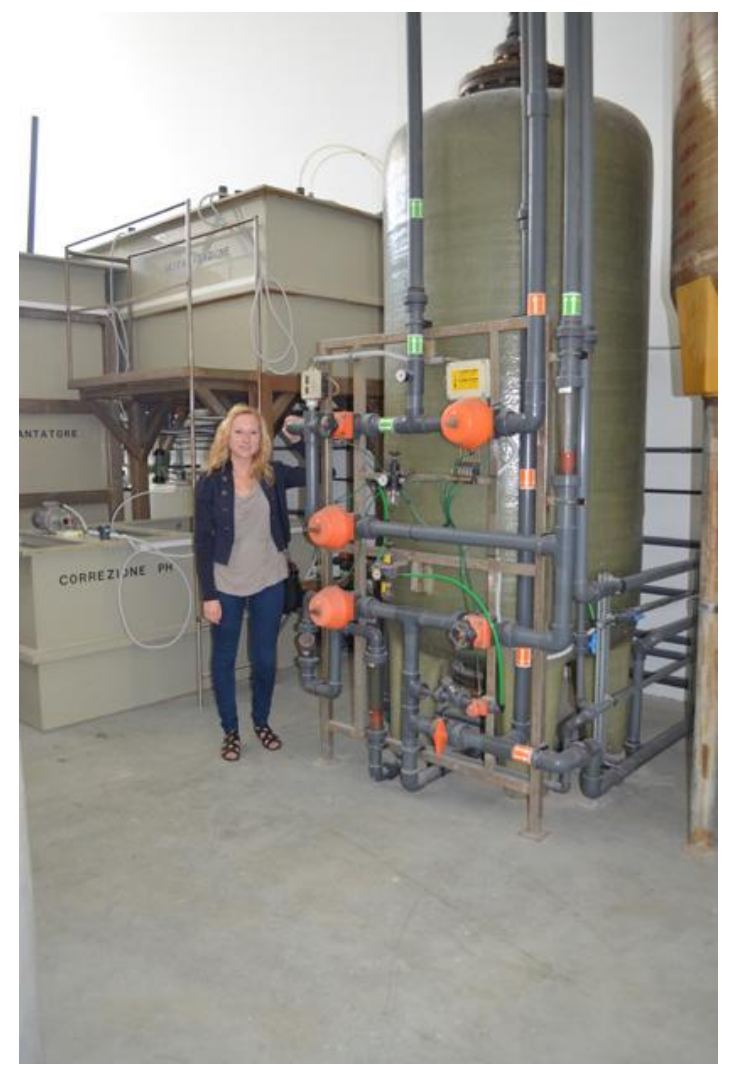

Fig.12: Part of an advanced system for wastewater treatment (after the process of electroplating)

The aim is to create an opportunity for practical training of knowledge and skills at the Training Centre, which will gradually grow into a utility production area.

For the first time this year, additional time for work placement in a volume of 240 hours is envisaged. During this time students will be divided into groups of 10 to 15 people (Figure 5), each group will have an academic mentor (lecturer from the University) and a mentor from the company. Each student will have the right to choose his academic mentor and a company in which to conduct this work placement. Reports on the results will be performed in specially approved by the Ministry of Education diaries.

Outstanding students will be offered permanent employment depending on the needs of the company.

\section{RESULTS}

On the territory of the companies "Mechatronica", "Micron" and "Elna", under the direction of Assoc. Prof. N. Nenov, five-month work placements of students from the Higher Technical School in Rezekne (Republic of Latvia) have been carried out for three years within the "Erasmus" Program. 
The results of the placements are as follows: $1 /$ students have the opportunity to get familiar in practice with almost all items related to their training as future professionals in the field of mechatronics and the training is conducted at the highest international level; 2/during the period of practical training prerequisites are created for solving some production problems enabling real and independent assessment of the students' knowledge and skills. 3/from the psychological and social point of view, communication with workers from other countries is very important both for students and for employees. This makes the working team more flexible and sociable and creates additional prerequisites enhancing its performance.

\section{CONCLUSIONS}

Each country seeks to increase the welfare of its citizens. In the context of the 21-st century it can be done in a peaceful and democratic way only through proper economic development of the country, using its characteristic natural resources. The development of the economy, in turn, can be guaranteed only by boosting productivity and quality in both the private and public sector. The real economic growth can be achieved based on the knowledge and experience of a growing number of well-trained specialists. This would lead to the development of the market economy not only in the developed European countries, but also in Bulgaria.

Ultimately, this will give a new look to the European Union, will make it stronger and more diverse, and perhaps with a better and real future.

\section{REFERENCES}

[1] Petrova D., Higher productivity of labor and competitive power on firm used motivation of staff through involvement in concept oriented change processes, $38^{\text {th }}$ IGIP Symposium $-Q^{2}$ of $E^{2}$, Quality and Quantity of Engineering Education, September 6-9, 2009, Graz, Austria, Fachhochschule der Wirtschaft CAMPUS 02 Graz, ISBN: 978-3-85295-035-8, pp. 291-299

[2] Higher Education Act

[3] School Education Act 